\title{
Dr Edward James Prokipchuk
}

\author{
Clifford Ottaway MD PhD FRCPC
}

E dward Prokipchuk MD FRCP FACP died May 28, 2009, at 80 years of age. Ed, often called 'Prok' by his many friends and colleagues, was a vital part of Gastroenterology at St Michael's Hospital and the University of Toronto (Toronto, Ontario) for more than 30 years. He graduated from the University of Western Ontario (London, Ontario) in 1954 and trained as a physician in Toronto, Montreal (Quebec), London and Baltimore (USA). Ed joined St Michael's Hospital in 1963 and was the Head of the Department of Gastroenterology from 1968 to 1990. He was the consummate clinician, an outstanding teacher and a pioneer.

Ed was a founder of the gastroenterology training program at St Michael's Hospital and the University of Toronto. Ed taught gastroenterology, he taught commitment and he taught compassion. The gastroenterology trainees who studied with Prok are active in gastroenterology from coast to coast, but they will remember the detailed questioning and patient focus that Ed always brought to the bedside.

Ed was renowned for his encyclopedic knowledge, and his passion for excellence in patient care and medical education. He received a Distinguished Service Award from the Canadian Association of Gastroenterology in 1995.

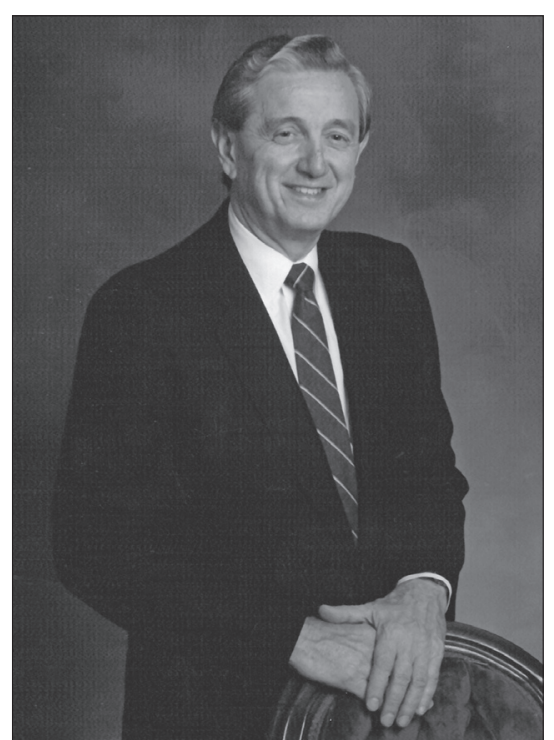

Ed was diagnosed with a familial form of kidney disease almost 50 years ago. In his last decade of life, he suffered many forms of illness, but always with persistent good humour and optimism. He leaves his wife Mary (née Jacobs), his children Debbie and David, and his grandchildren Scott and Lauren.

Canadian Gastroenterology has lost a friend, a colleague, a teacher, a leader and a man who always believed in the future.

St Michael's Hospital, Toronto, Ontario

Correspondence: Dr Clifford Ottaway, Department of Gastroenterology, St Michael's Hospital, Room 16302, 30 Bond Street, Toronto, Ontario M5B 1W8. Telephone 416-864-5684, 


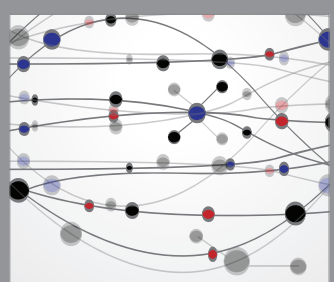

The Scientific World Journal
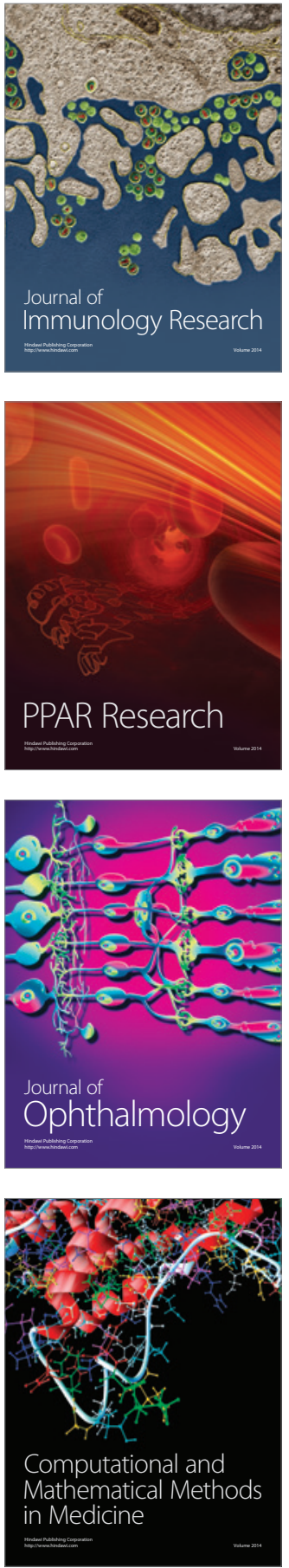

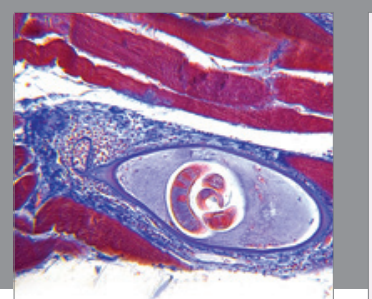

Gastroenterology Research and Practice

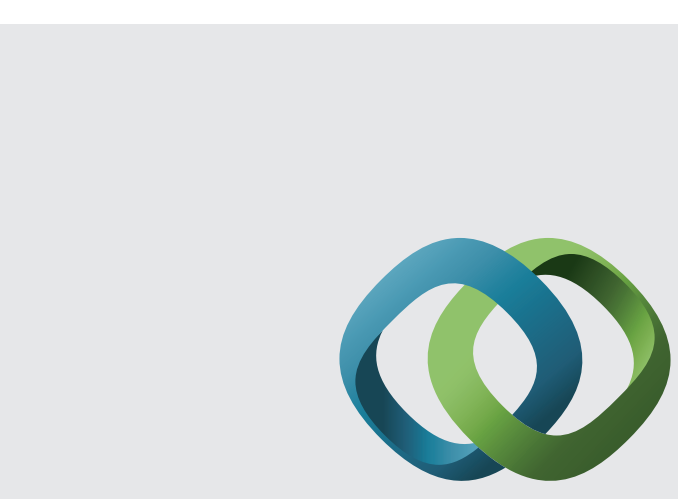

\section{Hindawi}

Submit your manuscripts at

http://www.hindawi.com
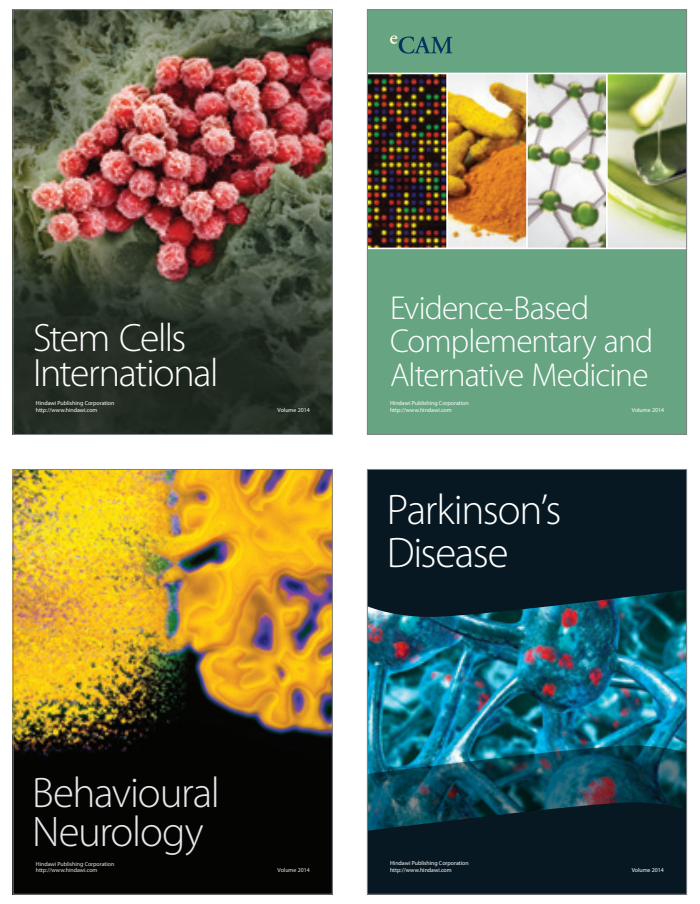
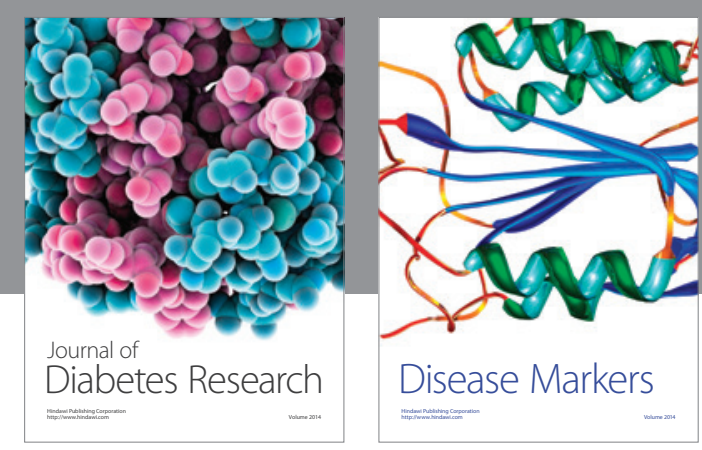

Disease Markers
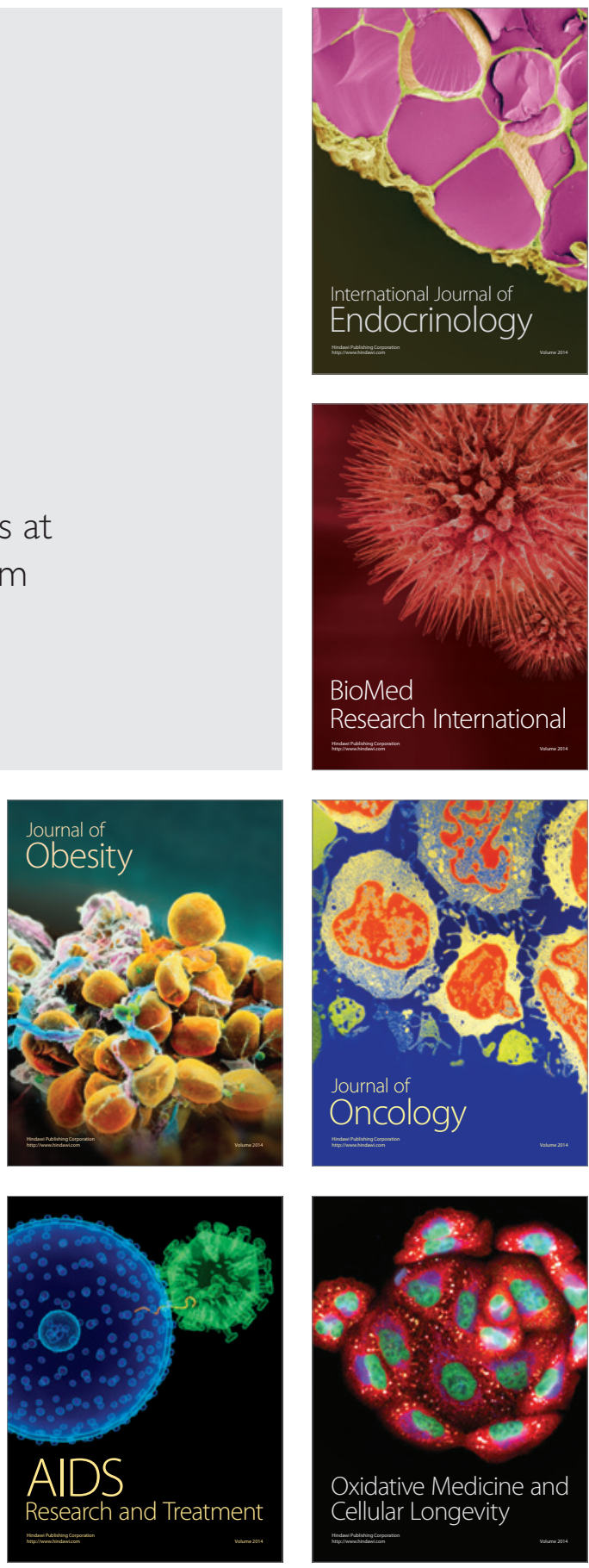